\title{
PERPUSTAKAAN DIGITAL BUDAYA INDONESIA: PERAN MASYARAKAT DAN KOMUNITAS MELINDUNGI DAN MELESTARIKAN BUDAYA INDONESIA
}

\author{
Tiara Kusumaningtiyas ${ }^{1}$, Nurazizah ${ }^{2}$ \\ Fakultas Vokasi, Universitas Airlangga, Surabaya, Indonesia ${ }^{1}$ \\ Perpustakaan Nasional Republik Indonesia, Jakarta, Indonesia ${ }^{2}$ \\ tiarakusumaningtiyas@vokasi.unair.ac.id¹ azzindah@gmail.com ${ }^{2}$
}

\begin{abstract}
Abstrak
Indonesia merupakan negara dengan keberagaman jumlah budaya, keberagaman ini belum mampu di identifikasi dan di data, sehingga dikhawatirkan budaya-budaya tersebut akan tergerus globalisasi atau diklaim oleh pihak lain. Perpustakaan Digital Budaya Indonesia dengan konsep Virtual Community melakukan pendataan budaya yang melibatkan masyarakat dan komunitas dalam pelestarian budaya Indonesia. Artikel ini akan mendeskripsikan bagaimana Perpustakaan Digital Budaya Indonesia melalui situs www.budaya-indonesia.org melakukan pelestarian budaya dengan kontribusi dari seluruh elemen masyarakat. Penelitian ini menggunakan pendekatan kualitatif dengan metode observasi web dan studi literatur sebagai teknik pengumpulan data. Hasil penelitian menunjukan bahwa upaya pelestarian budaya oleh masyarakat antara lain melalui pendokumentasian budaya, pencatatan dan inventarisasi data budaya, akses dan pemanfaatan data budaya dan manfaat data budaya yang dikumpulkan di Perpustakaan Digital Budaya Indonesia memberikan banyak manfaat bagi bangsa Indonesia, diantaranya menunjukan keberagaman budaya, mencatat berbagai warisan budaya dan meminimalisir klaim terhadap budaya Indonesia dari pihak asing.
\end{abstract}

\section{Abstract}

Indonesia is a country with cultural diversity, this diversity has not been able to be identified and registered, so it is feared those cultures will be eroded by globalization or claimed by another party. Perpustakaan Digital Budaya Indonesia with the concept of Virtual Community to collect data on culture which involves people and communities in the preservation of the

\section{KEL INFO}

Diterima: 20 Januari 2022

Direvisi: 23 Januari 2022

Disetujui: 24 Januari 2022

\section{Kata Kunci:}

Perpustakaan Digital, Virtual Community, Warisan Budaya, Pelestarian

Keywords:

Digital Library, Virtual Community, Cultural Heritage, Preservation 
culture of Indonesia. This article is going to describe how Perpustakaan Digital Budaya Indonesia through budayaindonesia.org performs cultural preservation with the contribution of all elements of society. This study is using a qualitative approach with web observation and literature study as data collection techniques. The results showed that efforts to conserve the culture of the community by documenting the cultural records and inventory data, access and utilization of cultural data and the benefits of cultural data gathered at the Perpustakaan Digital Budaya Indonesia provide many benefits to Indonesia, among others present in various cultures, record various cultural heritages and minimize claims against Indonesian culture from foreign parties.

\section{Pendahuluan}

\section{Latar Belakang}

Membahas mengenai Indonesia, salah satu hal yang menjadi kebanggaan sebagai bagian dari Indonesia adalah keberagaman suku bangsa. Berdasarkan data dari Badan Pusat Statistik (BPS) pada tahun 2013 (BPS, 2015), terdapat sedikitnya 633 kelompok suku besar di Indonesia. Jika data tersebut diperinci hingga tingkat subsuku, angka tersebut membengkak menjadi sekitar 1331 kelompok, dimana setiap kelompok suku tersebut memiliki beragam warisan budaya. Warisan budaya adalah keseluruhan peninggalan kebudayaan yang memiliki nilai penting sejarah, ilmu pengetahuan dan teknologi dan/ seni. Tak terbayangkan berapa jumlah warisan budaya Indonesia yang terletak di \pm 17.508 pulau yang membentang sejauh 7.365 km (Masyarakat Penulis Ilmu Pengetahuan dan Teknologi, 2009) tersebut. Bayangkan jika satu suku bangsa saja memiliki bahasa, nilai, kebiasaan, kuliner dan hasil kebudayaan yang berbeda antara satu dan lainnya.

Warisan budaya yang merupakan identitas, kebanggaan, dan peluang usaha bagi berbagai sektor perlu dilindungi dan dilestarikan. Tentu saja peran dan usaha dari Lembaga Pemerintahan dalam melindungi warisan budaya Indonesia terus diupayakan hingga saat ini. Usaha dalam melindungi berbagai bentuk warisan budaya Indonesia tidak terbatas pada capturing budaya saja, tetapi sharing informasi terkait budaya yang dimiliki akan memberikan dampak baik bagi bangsa Indonesia. Apalagi saat ini, perkembangan teknologi mempermudah penyebaran informasi dikalangan masyarakat. Publikasi budaya melalui teknologi (website) juga dapat meminimalisir klaim budaya Indonesia oleh Negara lain. Seperti yang telah dilakukan Perpustakaan Nasional Indonesia melalui website http://coe.perpusnas.go.id/ dan Kementrian Pendidikan dan Kebudayaan dengan website http://kebudayaanindonesia.net/.

Namun, upaya dalam melindungi
budaya Indonesia oleh $\begin{array}{r}\text { Lembaga } \\ \text { Pemerintahan tidak mampu ditangani }\end{array}$
secara keseluruhan. Banyak kendala yang
harus dihadapi, seperti keberagaman
jumlah budaya, keadaan geografis,
keterbatasan sumber daya manusia dan
pendanaan merupakan beberapa faktor
yang mendasari sulitnya menjangkau dan
melakukan pendataan terhadap budaya di
Indonesia secara keseluruhan.


Sebuah trobosan inovasi hadir dari sekelompok masyarakat karena kekhawatiran mereka terhadap beberapa hal, yaitu ancaman terhadap budaya-budaya Indonesia yang "mungkin" akan hilang karena belum mampu dikenalkan pada masyarakat dan diklaim oleh pihak/Negara lain. Selain itu, tantangan terhadap kualitas dan kuantitas penelitian budaya dan pengembangan inovasi ekonomi kreatif berbasis kekayaan budaya adalah beberapa hal yang mendasari kegiatan Gerakan Sejuta Data Budaya oleh Yayasan Sobat Budaya. Melalui situs budaya-indonesia.org atau Perpustakaan Digital Budaya Indonesia (PDBI) yang diperuntukkan bagi masyarakat Indonesia untuk berpartisipasi dan terlibat dalam menghimpun data-data budaya Indonesia.

Artikel ini akan mendeskripsikan bagaimana situs budaya-indonesia.org sebagai Perpustakaan Digital menggunakan konsep vitual community dengan memberikan peluang bagi masyarakat atau komunitas dalam berpartisipasi, berkontribusi dan berperan untuk membangun data-data budaya Indonesia yang bertujuan melindungi dan melestarikan budaya Indonesia melalui penghimpunan data-data budaya Indonesia dari kontribusi masyarakat. Virtual community adalah perkumpulan sosial yang melakukan interaksi, hubungan antar anggota dan diskusi publik yang terbentuk melalui jaringan internet, menghasilkan hubungan pribadi dan rasa komunitas (Ellis, Oldridge dan Vasconcelos, 2004; Kim, 2009).

\section{Tinjauan Literatur}

\subsection{Perpustakaan Digital}

\begin{tabular}{lll}
\multicolumn{2}{c}{ Perkembangan } & teknologi dan \\
implementasinya & di & perpustakaan \\
melahirkan konsep & baru dalam dunia
\end{tabular}

perpustakaan. Perpustakaan digital merupakan salah satu bentuk implementasi teknologi di perpustakaan. Perpustakaan digital bukanlah satu kesatuan, memerlukan teknologi untuk menghubungkan sumber-sumber dari berbagai layanan yang terbuka bagi pengguna (ARL, 1995) dan informasi tersebut disimpan dalam format digital (teks, gambar, rekaman suara, musik, video dan lainnya) yang dapat diakses melalui jaringan (Arms, 200o). Selain itu, pengguna dapat mengakses (creating, searcing and using information) semua sumber informasi yang dibutuhkan dari manapun, kapanpun dan dengan apapun (Jindal, 2010).

Bukan hanya memudahkan dalam mengakses informasi, perpustakaan digital merupakan bagian dari peservasi, terutama karena sumber informasi yang dimiliki merupakan format digital. Sumber-sumber digital tersebut lebih mudah untuk dilestarikan, terutama karena jumlah salinan yang tak terbatas dan keadaannya lebih lifelong (Jindal, 2010). Perpustakaan baik traditional maupun digital memiliki peran sebagai pusat budaya, atau lembaga pelestari budaya yang koleksinya berupa heritage of humanity, records of triumphs and failures, intellectual scientist and achievements and collective memory (World Bank, dalam Ekwelem, Okafor and Ukwoma, 2011).

Menurut Hoffman (--) pelestarian budaya mencakup berbagai aspek seperti hak asasi manusia, toleransi, pengembangan dan perlindungan situs budaya dan artefak, serta kekayaan hak intelektual untuk bahasa dan seni budaya. UNESCO yang merupakan organisasi persatuan negara-negara memiliki gagasan untuk melindungi dan melestarikan hasil budaya bangsa. Inti dari program UNSECO adalah pengakuan dari hubungan antara budaya dan tujuan yang 
lebih luas masyarakat dunia. Hormat, toleransi dan perlindungan budaya merupakan inti dari mandat UNESCO. Terdapat 4 alasan pelestarian warisan budaya, yaitu: 1). The cultural memory. Pelestarian warisan budaya mempertahankan bukti sejarah fisik dan mentransfer nilai pengetahuan dan keterampilan nenek moyang; 2). The convenient proximity. Pelestarian warisan budaya dapat mendukung interaksi antara lingkungan, orang dan kegiatan masyarakat; 3). The environment diversity. Sebagai identitas masyarakat lokal atau perbedaan, pelestarian akan mempertahankan artefak lokal dan seniman lokal di antara aliran pembangunan perkotaan. 4). The Economic Gain. Pelestarian memberikan dua keuntungan ekonomi, yaitu untuk menghemat biaya bangunan baru dan atraksi untuk pengunjung (Prompayyuk dan Chairattananon, 2016). Selanjutnya, upaya melestarikan warisan budaya juga harus bertujuan untuk melestarikan tidak hanya benda-benda fisik, seperti bangunan dan lingkungan mereka, tetapi juga hal-hal tak berwujud seperti bahasa seni, dan adat istiadat (Mat Radzuan, 2014).

\subsection{Warisan Budaya}

Budaya menurut UNESCO (2017) adalah "[Culture] is that complex whole which includes knowledge, beliefs, arts, morals, laws, customs, and any other capabilities and habits acquired by [a human] as a member of society.". Budaya bersifat unik dan merupakan ciri sebuah bangsa dari generasi sebelumnya, tentu saja budaya merupakan bentuk dari peninggalan atau warisan untuk generasi saat ini. Warisan budaya merupakan ekspresi dari cara hidup yang dikembangkan oleh komunitas dan diwariskan dari generasi ke generasi, baik itu kebiasaan, practices, places, objects, artistic expressions and values (ICOMOS,
2002). UNESCO mendefinisikan warisan budaya adalah “... the legacy of physical artefacts and intangible attributes of a group or society that are inherited from past generations, maintained in the present and bestowed for the benefit of future generations."

Menurut UNESCO (2017) kategori warisan budaya dibagi menjadi dua kategori, yaitu Tangible cultural heritage (movable cultural heritage, immovable cultural heritage dan underwater cultural heritage) and Intangible cultural heritage. Kategori yang disebutkan tersebut terwujud dalam berbagai bentuk budaya. Tangible heritage berbentuk fisik temasuk bangunan dan tempat bersejarah, monumen, artefak dan lainnya. Intangible heritange adalah "traditions or living expressions inherited from ancestors and pasess on to our descendants" bentuknya dapat berupa ritual, oral traditions, social practices, resep masakan tradisional, performing arts, etc.

\subsection{Virtual Community}

Sejak internet dapat digunakan secara komersil, perkembangan komunikasi informasi menjadi sangat cepat, salah satu dampaknya adalah virtual community. Virtual community adalah sebuah komunitas di dunia maya yang kegiatannya didukung oleh computer berbasis IT, berfokus pada komunikasi dan interaksi oleh peserta dan menekankan pada hubungan antar anggota dalam komunitas dan peran IT (Yap and Bock, dalam Äkkinen, 2005). Meskipun belum ada standard yang dapat diterima secara luas mengenai community typology, namun dalam papernya Katrina Stanoevska-Slabeva dan Beat Schmid (2001) membagi tipe komunitas menjadi empat klasifikasi, yaitu Discussion communities (Pertukaran informasi mengacu sumber yang telah ditentukan), 
communities (mengacu pada komunitas yang berjuang untuk mencapai tujuan bersama melalui kerjasama), Virtual worlds (dunia fantasia tau games) and Hybrid communities (integrasi dari beberapa jenis yang disebutkan).

Komunitas virtual adalah komunitas yang berinteraksi melalui media computer dan internet yang didasarkan dengan kepentingan bersama, daripada karakteristik social yang sama, komunitas ini lebih berorientasi pada penyediaan informasi (Ellis, Oldridge, dan Vasconcelos, 2015). Definisi lain mengenai Virtual Community yaitu "...groups of people with common interests and practices that communicate regularly and for some duration in an organized way over the Internet through a common location or mechanism" (Ridings et. al, 2002). Figallo (dalam Ridings et, al, 2017) menyatakan bahwa Virtual Community adalah bagian dari kelompok sosial besar, merasakan jaringan hubungan yang terjalin dengan anggota lain, melakukan pertukaran berkelanjutan dengan anggota lain tentang hal-hal yang umumnya menjadi ketertarikan bersama (seperti informasi tentang hobi bersama), dan memiliki hubungan yang langgeng dengan orang lain. Sehingga dapat disimpulkan bahwa virtual community adalah sekelompok orang yang memiliki ketertarikan pada "hal" yang sama dan membentuk kelompok melakukan interaksi dan berkomunikasi melalui media komputer dan internet.

\subsection{Pelestarian Budaya}

Pelestarian menurut Rancangan UndangUndang tentang Kebudayaan adalah upaya dinamis yang meliputi perlindungan, pengembangan dan pemanfaatan. Dalam
Peraturan Menteri Dalam Negeri No. 25 Tahun 2007 tentang Pedoman Pelestarian dan Pengembangan Adat Istiadat dan Nilai Sosial Budaya Masyarakat, pelestarian adalah upaya untuk menjaga dan memelihara adat istiadat dan nilai sosial budaya masyarakat yang bersangkutan, terutama nilai-nilai etika, moral, dan adab yang merupakan inti dari adat istiadat, kebiasaan-kebiasaan dalam masyarakat, dan lembaga adat agar keberadaannya tetap terjaga dan berlanjut. Menurut Hoffman (-) pelestarian budaya mencakup berbagai aspek seperti hak asasi manusia, toleransi, pengembangan dan perlindungan situs budaya dan artefak, serta kekayaan hak intelektual untuk bahasa dan seni budaya. UNESCO yang merupakan organisasi persatuan negara-negara memiliki gagasan untuk melindungi dan melestarikan hasil budaya bangsa. Inti dari program UNSECO adalah pengakuan dari hubungan antara budaya dan tujuan yang lebih luas masyarakat dunia. Hormat, toleransi dan perlindungan budaya merupakan pusat dari mandat UNESCO.

Terdapat 4 alasan pelestarian warisan budaya, yaitu: 1). The cultural memory. Pelestarian warisan budaya mempertahankan bukti sejarah fisik dan mentransfer nilai pengetahuan dan keterampilan nenek moyang; 2). The convenient proximity. Pelestarian warisan budaya dapat mendukung interaksi antara lingkungan, orang dan kegiatan masyarakat; 3). The environment diversity. Sebagai identitas masyarakat lokal atau perbedaan, pelestarian akan mempertahankan artefak lokal dan seniman lokal di antara aliran pembangunan perkotaan. 4). The Economic Gain. Pelestarian memberikan dua keuntungan ekonomi kepada masyarakat, yaitu untuk menghemat biaya bangunan baru dan atraksi untuk pengunjung (Prompayyuk dan Chairattananon, 2016). 
Selanjutnya, upaya melestarikan warisan budaya juga harus bertujuan untuk melestarikan tidak hanya benda-benda fisik, seperti bangunan dan lingkungan mereka, tetapi juga hal-hal tak berwujud seperti bahasa seni, dan adat istiadat (Mat Radzuan et al, 2014).

\section{Metode Penelitian}

Penelitian ini menggunakan pendekatan kualitatif dengan metode observasi web dan studi literatur. Pengumpulan data melalui dokumendokumen terkait Perpustakaan Digital Budaya Indonesia yang berasal dari berbagai berita online, website budaya-indonesia.org dan website http://sobatbudaya.or.id/. Kemudian data-data tersebut dianalisis berdasarkan konsep virtual community dan hubungannya terhadap partisipasi masyarakat dan komunitas untuk melindungi dan melestarikan budaya Indonesia.

\section{Pembahasan \\ 4.1. Apa itu Perpustakaan Budaya Indonesia?}

Perpustakaan Digital Budaya Indonesia merupakan sebuah perpustakaan terbuka yang bersifat inisiatif dan partisipatif dari semua kontributor atau sobat budaya. Masyarakat dapat berpartisipasi menambahkan data melalui akun yang sebelumnya telah terdaftar. Tidak hanya professional dan penggiat budaya saja yang dapat mendaftar dan ikut berpartisipasi, namun semua elemen masyarakat diberikan kesempatan yang sama. Kontributor (sebutan bagi siapa saja yang telah berpartisipasi) dapat melakukan posting baru, perbaikan, berkomentar atau berdiskusi pada entri budaya. Bergabung menjadi kontributor sangat mudah, penjelasan lebih lanjut diberikan melalu media sosial youtube https://www.youtube.com/watch?v=Cc4 Kk 7A4j1U\&list=FLN6-

$\underline{\mathrm{PMJ}_{3}}$ 95va3bLwubd XQ\&index=1 untuk memudahkan masyarakat yang menjadi contributor baru dan bergabung menambahkan data (Sobat Budaya Fondation, 2017).

$\begin{array}{rrr}\text { Perpustakaan } & \begin{array}{c}\text { Digital } \\ \text { Indonesia melalui } \\ \text { situs }\end{array} \text { budaya- }\end{array}$ indonesia.org merupakan media bagi "Gerakan Sejuta Data Budaya" Kegiatan proteksi dan konservasi dengan melakukan pendataan terhadap elemen kebudayaan yang ada di Indonesia (http://sobatbudaya.or.id/sejuta-databudaya/) yang diinisiai oleh Indonesia Archiphipelagi Cultural Initiative (IACI) yang dimotori oleh Bandung Fe Institute (BFI). Gerakan ini mendapat apresiasi dari Pemerintah, yaitu Presiden saat itu Susilo Bambang Yudhoyono yang disampaikan oleh Andi Arief, Staff Khusus Presiden bidang Bantuan Sosial dan Bencana, saat peluncuran "Gerakan Sejuta Data Budaya" di Istana Negara (2011). Kegiatan Gerakan Sejuta Data Budaya melibatkan Yayasan Sobat Budaya dan tentu saja partisipasi publik.

Setelah 13 tahun mengkampanyekan Gerakan Sejuta Data Budaya, telah terkumpul informasi budaya Indonesia yang tersebar dalam beberapa jenis, yaitu Alat musik 1.907 data, cerita rakyat 3.497 data, makanan dan minuman 35.017, motif kain 1.547 data, music dan lagu 1.620 data, naskah kuno dna prasasti 1.687 data, ornament 882 data, paakian tradisional 745 data, permainan tradisional 1,262 data, produk arsitektur 2.252 data, ritual 3336 data, seni pertunjukan 1.104 data, senjata dan alat perang 758 data, tarian 2.365 data, dan tata cara pengobatan dan pemeliharaan kesehatan sebanyak 502 data, 
jadi total keseluruhan data yang telah terhimpun berjumlah 58,481 data per 12 November 2021. Berkas data dalam Perpustakaan Budaya Indonesia di situs budaya-indonesia.org, bahkan ribuan data tersebut saat ini telah dikumpulkan, diteliti dan dikembangkan menjadi beragam temuan dan inovasi. Bukan saja mengumpulkan data budaya Indonesia, Gerakan Sejuta Data Budaya mendaftarkan data-data tersebut ke World Intellectual Property Organization (WIPO) dengan tujuan untuk bentuk perlindungan budaya dari klaim pihak lain dan menjadi dasar penelitian selanjutnya.

\section{Gambar 1. Halaman Home Perpustakaan Digital Budaya Indonesia}

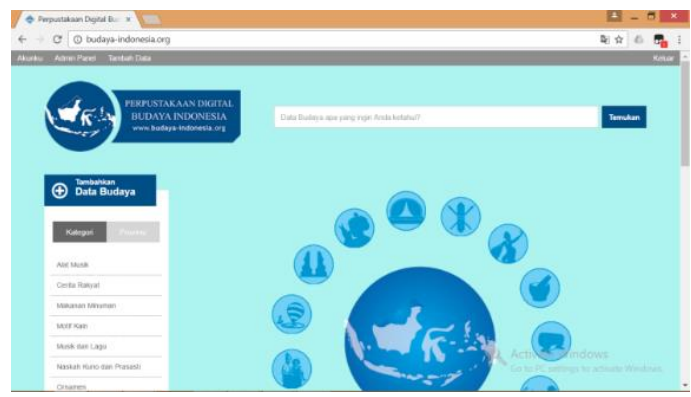

Selain dapat diakses melalui website budaya-indonesia.org Perpustakaan Digital Budaya Indonesi ajuga dapat diakses atau digunakan melalui aplikasi smartphone (iOS, Android, and Blackberry). Koleksi data budaya yang dimiliki Perpustakaan Digital Budaya Indonesia dibagi berdasarkan kategori, yaitu: Tarian, Ritual, Ornamen, Motif Kain, Alat Musik, Cerita Rakyat, Musik dan Lagu, Makanan dan Minuman, Seni Pertunjukan, Produk Arsitektur, Pakaian Tradisional, Permainan Tradisional, Senjata dan Alat Perang, Naskah Kuno dan Prasasti dan yang terakhir Tata cara Pengobatan dan Pemeliharaan Kesehatan. Kategori lain yang digunakan yaitu berdasarkan daerah asal atau provinsi di Indonesia (34 provinsi).
Pembangunan Perpustakaan Digital Budaya Indonesia memiliki 3 pilar yang ingin diusung, yaitu: 1). Akuisisi sains dan teknologi mutakhir untuk keindonesiaan berbasis budaya. Hal ini dikarenakan pencatatan data secara digital akan mendukung dan memudahkan berbagai upaya untuk menghubungkan budaya tradisional dengan hal-hal yang mutakhir di era informasi; 2). Perlindungan budaya tradisional di era informasi. Pendataan dan pencatatan secara digital memungkinkan inovasi-inovasi kolektif dalam rantai tradisi budaya menjadi tercacah, dan konflik klaim budaya secara komersial yang terjadi dengan memanfaatkan ketidaktahuan dapat dikurangi; dan 3). Ekonomi yang berlandaskan kreatifitas dan inovasi berdasarkan warisan budaya tradisi. Dengan melihat pada situs Perpustakaan Digital Indonesia, setiap orang dapat menambah pengetahuan mengenai budaya tertentu di Indonesia dan memunculkan kreatifitas dan inovasi dengan memanfaatkan hasil budaya tersebut.

\subsection{Perpustakaan Digital Budaya Indonesia sebagai Virtual Community}

Mengusung konsep inisiatif dan partisipatif, Perpustakaan Budaya Digital Indonesia merupakan salah satu bentuk dari Virtual Community, tepatnya adalah virtual community tipe Discussion Communities. Pada Perpustakaan Digital Budaya Indonesia, terdapat beberapa fitur yang mendukung contributor untuk melakukan aktifitas komunikasi dan interaksi, mengenai budaya Indonesia yang didukung oleh Information Technology untuk tujuan bersama (Äkkinen, 2005).

Perpustakaan Digital Budaya Indonesia memang bersifat bebas, dimana semua kontributor dapat menambah atau 
unggah data budaya. Tetapi, semua kegiatan penambahan dan pengunggahan data tetap dalam pengawasan pihak-pihak yang bertanggungjawab. Setiap entri data budaya yang sudah dimasukkan kedalam situs boleh diedit oleh siapapun, setidaknya bisa untuk dikomentari isinya. Kekeliruan data oleh satu orang dapat diperbaiki oleh orang lain. Setiap orang dapat saling suntingmenyunting data yang ada di dalam situs tersebut. Jika ada perbedaan pendapat yang tak kunjung selesai, solusi diambil melalui komentar-komentar dan diskusi yang tempatnya telah disediakan. Perbedaan pendapat didalam menilai dan memahami data merupakan dinamika yang sangat baik dan penting bagi keberlangungan suatu budaya.

Perpustakaan digital budaya Indonesia merupakan satu wadah bagi komunitas-komunitas untuk berpartisipasi mengunggah dan mendiskusikan data hasil budaya. Komunitas ini menyebut diri sebagai "Komunitas Sobat Budaya." Komunitas-komunitas ini muncul juga diberbagai daerah di kepulauan Indonesia. Semua sobat budaya berjejaring dan bekerjasama dalam membangun dan melestarikan budaya tradisional dengan cara yang tidak tradisional, yaitu melihat budaya sebagai informasi dan menyimpannya bersama secara digital.

Berikut ini tampilan Perpustakaan Digital Budaya (budaya-indonesia.org) sebagai Virtual Community:

1. Tambah Data Budaya

Kontributor atau masyarakat yang sudah tergabung dan memiliki akun, dapat menambahkan data mengenai budaya Indonesia dengan mengisi form seperti yang tertera pada gambar. Pada menu keterangan dapat dijelaskan mengenai deskripsi dari data yang akan diunggah pada website.

\section{Gambar 2}

Form tambah data budaya

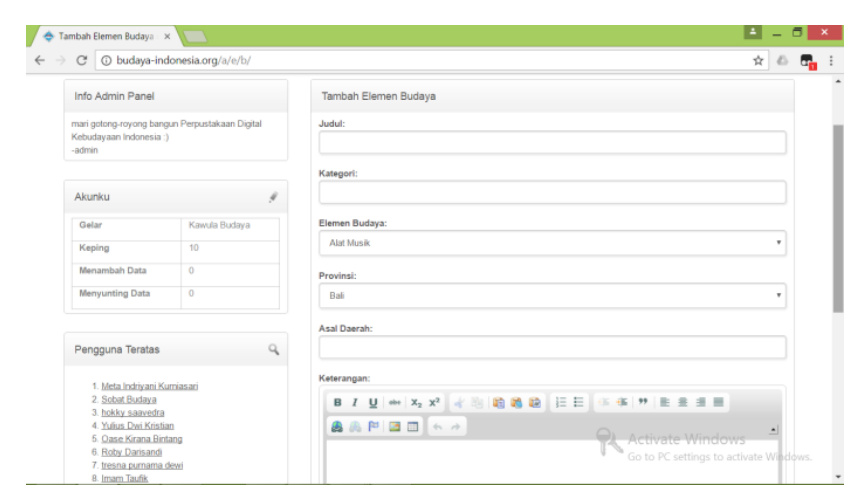

2. Diskusi

Perpustakaan Digital Budaya

Indonesia memberikan kesempatan bagi semua contributor melakukan diskusi, baik berupa pertanyaan, atau jawaban terhadap terhadap sebuah data budaya. Diskusi yang berlangsung akan tetap diawasi oleh pihak pengawas dan yayasan. Setiap orang yang telah begabung menjadi sobat budaya dapat memilai diskusi dengan memilih data apa yang ingin dikomentari, kemudian dapat menuliskan pesan diskusi pada kolom yang disediakan sesuai dengan gambar 3 dan gambar 4 . 


\section{Gambar 3: Daftar pengawasan diskusi yang berlangsung}

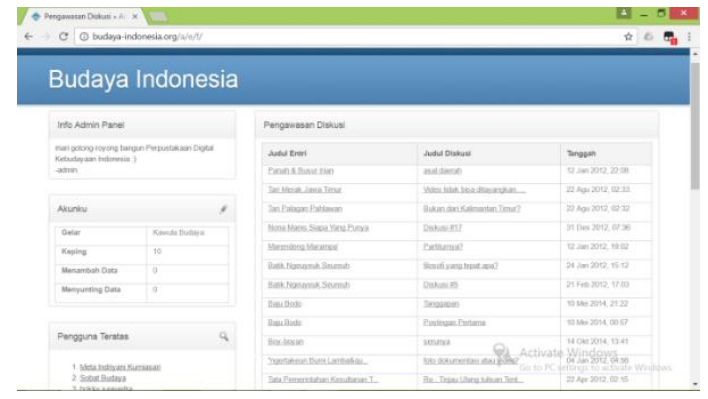

Gambar 4

Form memulai diskusi

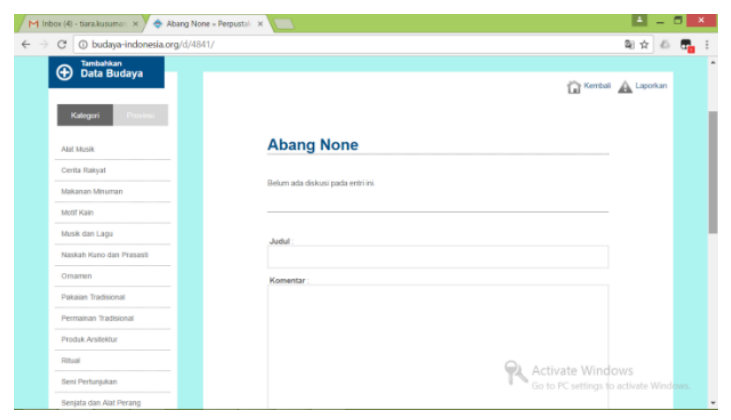

3. Melaporkan Data

Selain dapat menambah dan menyunting data budaya, kontributor dapat berpartisipasi mengawasi data budaya tersebut melalui fitur pelaporan data, sehingga pengawasan yang lebih ketata dapat dilakukan

\section{Gambar 5} Form pelaporan data

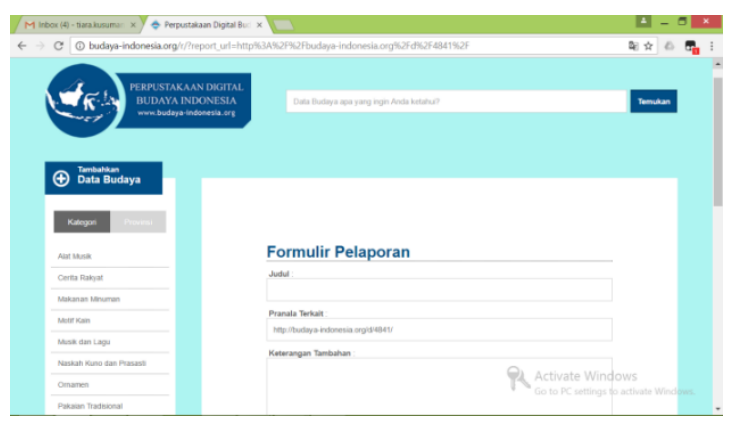

4. $\quad$ Profile Setting

Umumnya pada sebuah virtual community, Perpustakaan Digital Budaya Indonesia memberikan layanan bagi kontributor untuk mengatur profil akun mereka.

\section{Gambar 6}

Form pengaturan profil

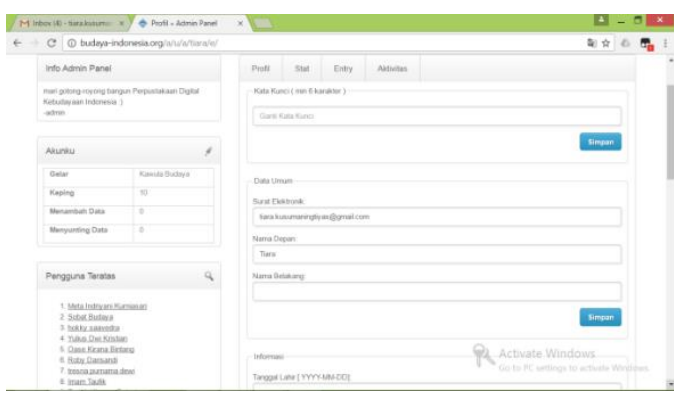

Berdasarkan penjelasan tersebut, Perpustakaan Digital Budaya Indonesia merupakan salah satu Virtual Community, seperti yang dijelaskan oleh Whittaker, Issacs and O’Day (1997) karena memiliki ciri-ciri sebagai berikut: 1) memiliki tujuan bersama, ketertarikan yang sama, kebutuhan yang sama dan memiliki alasan kuat menjadi bagian dari komunitas tersebut; 2) akses ke sumbersaya bersama, dan terdapat kebijakan yang menentukan akses ke sumberdaya tersebut; 3) ada timbal balik informasi, dukungan dan layanan antar angora dan; 4) memiliki konteks konvensi sosial, bahasa, dan protokol yang sama (dalam Gupta dan Kim, 2004)

\subsection{Upaya Pelestarian Budaya Melalui Perpustakaan Digital Budaya Indonesia}

Pelestarian secara sederhana dapat berarti memelihara dan menyimpan sesuatu agar tidak hilang atau rusak akibat perkembangan zaman. Pelestarian bertujuan untuk menjadikan sesuatu tetap ada seperti aslinya, tidak rusak atau hilang 
dan dapat bertahan untuk penggunaan di masa yang akan datang. Pelestarian budaya bangsa dilakukan untuk memelihara dan melindungi budaya-budaya Indonesia, terutama agar warisan budaya tidak hilang atau ditinggalkan karena globalisasi atau diklaim negara lain.

Pelestarian budaya Indonesia secara jelas telah diatur dalam berbagai produk hukum pemerintah, terutama berisi bagi lembaga-lembaga pemerintah dalam melakukan pelestarian budaya. Meskipun begitu, upaya pelestarian budaya tidak telepas dari peran dan partisipasi masyarakat. Wujud nyata dari upaya pelestarian budaya oleh masyarakat dan komunitas dilakukan melalui Perpustakaan Digital Budaya Indonesia. Menggunakan konsep Virtual Community, Perpustakaan Digital Budaya Indonesia menyediakan beragam fitur dan memberikan kesempatan bagi masyarakat dan komunitas untuk capture information dan sharing information mengenai Budaya Indonesia.

Upaya pelestarian budaya dilakukan oleh masyarakat yang tergabung dalam Virtual Community Perpustakaan Digital Budaya Indonesia. Masyarakat yang tergabung dalam komunitas tersebut secara bergotong-royong berupaya untuk melakukan pelestarian hasil budaya bangsa dengan mendata dan memasukkan hasil budaya bangsa Indonesia ke dalam web Perpustaakaan Digital Budaya Indonesia. Upaya ini dilakukan secara bersama-sama, melibatkan banyak pihak karena tidak mungkin untuk melakukan pengumpulan data hasil budaya bangsa sendirian. Keanekaragaman budaya bangsa Indonesia yang dimiliki sangat banyak dan beraneka ragam sehingga pencatatan dan pengumpulan budaya Indonesia dilakukan secara partisipatif dan bersama-sama.
Keberagaman budaya Indonesia sangat besar dibandingkan dengan negara lain, sehingga budaya Indonesia sangat rentan mengalami kepunahan jika tidak dilakukan upaya yang sistematis untuk melestarikan budaya yang ada. Menanggapi hal ini, masyarakat yang tergabung dalam virtual community Perpustakaan Digital Budaya Indonesia, melakukan gerakan Sejuta Data Budaya (SDB) yaitu sebuah gerakan yang dilandasi kesadaran akan perlunya sebuah pendataan terhadap elemen kebudayaan yang ada di Indonesia. Data yang telah terkumpul diharapkan memberikan manfaat untuk seluruh masyarakat Indonesia sebagai perangkat pertama dalam memperjuangkan perlindungan hukum untuk seluruh budaya nusantara. Selain itu, diharapkan dapat menumbuhkan inovasi-inovasi baru yang berlandaskan budaya nusantara.

Berikut ini, kegiatan yang dilakukan oleh masyarakat dan komunitas melalui Perpustakaan Digital Budaya Indonesia sebagai bentuk pelestarian terhadap budaya Indonesia, merujuk kepada konsep peservasi dan Peraturan Bersama Menteri Dalam Negeri dan Menteri kebudayaan dan Pariwisata No 40/42 Tahun 2009 Tentang Pedoman Pelestarian Kebudayaan:

1. Pendokumentasian budaya Melakukan capturing intangible Indonesian culture heritage, yaitu kegiatan pengalihan informasi dari bentuk tacit menjadi bentuk eksplisit. Seperti contoh, resep makanan, minuman, ritual, cerita rakyat, pengobatan tradisional dan lainnya yang diwariskan oleh generasi sebelumnya didokumentasikan dalam bentuk eksplisit. Mendokumentasi tangible culture heritage dalam format lain, seperti video dan foto. Contohnya 
adalah mendokumentasikan kain batik ke dalam bentuk foto.

2. Pencatatan dan Inventarisasi data budaya

Melakukan pendataan mengenai tangible and intangible culture heritage yang telah ditangkap ke dalam bentuk dokumen, kemudian diunggah ke database Perpustakaan Digital Budaya Indonesia.

3. Akses

Informasi mengenai culture heritage yang diunggah dalam bentuk dokumen (teks, gambar, video, audio, audio-video etc), mempermudah akses informasi bagi masyarakat, peneliti dan penggiat budaya.

4. Pemanfaatan data budaya Informasi dan data-data di Perpustakaan Budaya Indonesia menjadi sumber informasi awal untuk penelitian budaya dan memberikan kesempatan penelitian lebih jauh mengenai budaya serta pengembangan ekonomi berbasis budaya.

\section{Simpulan}

\begin{tabular}{cccc}
\multicolumn{2}{c}{ Perpustakaan } & Digital & Budaya \\
Indonesia & sebagai & sebuah & Virtual
\end{tabular} Community memberikan kontribusi positif terhadap Indonesia, sesuai dengan subjek yang menjadi fokus mereka, yaitu budaya. Melalui Gerakan Sejuta Data Budaya, komunitas ini melakukan berbagai kegiatan pelestarian budaya dengan cara yang berbeda. Usaha mereka dalam pelestarian budaya yaitu dengan pendokumentasian budaya, pencatatan dan inventarisasi data budaya, akses dan pemanfaatan data budaya. Data budaya yang dikumpulkan memberi banyak manfaat bagi bangsa Indonesia: pertama, melalui data tersebut bangsa Indonesia dapat menunjukan keberagaman budayanya; kedua, meminimalisir klaim terhadap budaya Indonesia dari pihak luar; ketiga, mencegah musnahnya budaya akibat globalisasi; keempat, memberikan manfaat dibidang pariwisata; dan kelima, menumbuhkan industri kreatif berbasis budaya. Secara keseluruhan, Perpustakaan Digital Budaya Indonesia telah memberikan kesempatan bagi masyarakat dan komunitas untuk bersama-sama membangun data budaya seperti yang telah dibahas pada bab sebelumnya. Budaya yang merupakan bagian dari kehidupan masyarakat, digunakan dan dimiliki bersama sebagai identitas bangsa. Sehingga masyarakat berperan penting dalam perlindungan, pengembangan dan pemanfaatan budaya.

\section{DAFTAR PUSTAKA}

Akkinen , Miia. (2005) "Conceptual Foundations of Online Communities Finlandia: Helsinki School of Economics." http://citeseerx.ist.psu.edu/viewdoc/d ownload?doi=10.1.1.462.3393\&rep $=\mathrm{r}$ ep $1 \&$ type $=$ pdf.

Association of Research Libraries. "Realizing Digital Libraries." http://old.arl.org/resources/pubs/mmp roceedings/126mmappen2 1995

Arms, William Y. (2000). Digital Libraries and Electronic Publishing. Unites States of America: The MIT Press.

Badan Pusat Statistik. Mengulik Data Suku di Indonesia (2015) https://www.bps.go.id/news/2015/ $11 / 18 / 127 /$ mengulik-data-suku-diindonesia.htm

Ekwelem, V. O, Okafor, V. N, and Ukwoma, S.C. (2011) "Peservation of Cultural Heritage: The Strategic Role 
of the Library and Information Science Prefessionala in South East Nigeria". Library Philosophy and Practice. http://www.webpages.uidaho.edu/ m bolin/ekwelem-okafor-ukwoma.htm

Ellis, D., Oldridge, R. and Vasconcelos, A. (2004). Community and virtual community. Ann. Rev. Info. Sci. Tech., 38: 145-186. doi:10.1002/aris.1440380104.

Ellis, David \& Oldridge, Rachel \& Vasconcelos, Ana. (2005) Community and Virtual Community. Annual Review of Information Science and Technology. 38 . 10.1002/aris.1440380104.

Gupta, Sumeet, and Hee-Woong Kim. (2004). "Virtual community: Concepts, implications, and future research directions." In Proceedings of the tenth Americas conference on information systems, vol. 10, pp. 2679-87.

International Council on Monuments and Sites. (2002). "A Cultural Heritage Manifesto." http://www.icomosuk.org/uploads/sidebar/PDF/A\%20Cu ltural\%20Heritage\%20Manifesto.pdf

Jindal, S. C. (2010). Digital Libraries and Scholarly Communication: A Perspective. Developing Sustainable Digital Libraries: Socio-Technical Perspectives: Socio-Technical Perspectives, 19.

Kementerian Dalam Negeri. Peraturan Menteri Dalam Negeri No. 52 Tahun 2007 tentang Pedoman Pelestarian dan Pengembangan Adat Istiadat dan Nilai Sosial Budaya Masyarakat
Kim, J. K. (2009). Knowledge behavior in virtual communites: Linking knowledge seeking and sharing (Order No. 3352851). Available from ProQuest Dissertations \& Theses Global. (304949453). http://search.proquest.com/docview/3 $\underline{04949453 \text { ? accountid }=17242}$

Masyarakat Penulis Ilmu Pengetahuan dan Teknologi (MAPIPTEK) (2009). Survei Pemetaan Nusantara. Jakarta: Badan Koordinasi Survei dan Pemetaan Nusantara (BAKOSRTAL)

Mat Radzuan, Indera Syahrul et al. (2014). "Cultural heritage, incentives system and the sustainable community: Lessons from Ogimachi Village, Japan."

http://www.ukm.edu.my/geografia/im ages/upload/14oke.geografia-jan2014-indera-edam.pdf

Okezone News. "Istana Luncurkan Gerakan Sejuta Data Budaya" http://news.okezone.com/read/2011/1 2/13/337/541787/istana-luncurkangerakan-sejuta-data-budaya 2011

Indonesia. Peraturan Bersama Menteri Dalam Negeri dan Menteri Kebudayaan dan pariwisata No. 40/42 Tahun 2009 tentang Pedoman Pelestarian Kebudayaan. http://ppid.kemendagri.go.id/frontend/upl oads/documents/10010000096 peraturan bersama menteri dalam negeri_dan $m$ enteri_kebudayaan_dan_pariwisata_no.42 _dan_no_40_2009.pdf.

Perpustakaan Digital Budaya Indonesia. http://budaya-indonesia.org/

Prompayuka, Supoj \& Chairattananon, Panayu. (2016). "Preservation of Cultural Heritage Community: Cases of Thailand and developed countries." http://remote- 
lib.ui.ac.id:2086/S1877042816314938 11-s2.0-S18770428163149382016

Ridings, C., Gefen, D., \& Arinze, B. (2002). Some antecedents and effects of trust in virtual communities. Journal of Strategic Information Systems, 11 (34), 271-295 DOI: https://doi.org/10.1016/S09638687(02)00021-5

Satu Data Indonesia. (2016) "Memajukan Kebudayaan Indonesia dengan Satu Data: Saatnya Berpartisipasi." http://data.go.id/konten/memajukankebudayaan-indonesia-dengan-satudata-saatnya-berpartisipasi/

Seadle, M., \& Greifeneder, E. (2007). Defining a digital library. Library $\mathrm{Hi}$ Tech, 25(2), 169. doi:http://dx.doi.org/10.1108/0737883 0710754938

Sobat Budaya. (2013) "Cara Menambah Entri di www.budaya-indonesi.org." https://www.youtube.com/playlist?list $=$ FLN6-PMJ3 95va3bLwubd XQ . (2017) "Sobat Budaya on Day Break MNC World News." https://www.youtube.com/results?sear ch_query=sobat+budaya + di + new

Sobat Budaya Foundation. (2017) "Gerakan Sejuta Data Budaya." http://sobatbudaya.or.id/sejuta-databudaya/
Stanoevska-Slabeva, K. (2002) Toward a community-oriented design of Internet platforms. International journal of electronic commerce, 6(3), 71-95.

Thomas-Hoffman, Elizabeth A. (--) "Cultural Preservation and Protection." http://www.mesacc.edu/ bricl07041/un/hs /culture.pdf

United Nations Educational, Scienctific and Cultural Organization (UNESCO). (2017). "What is Meant by cultural heritage?." http://www.unesco.org/new/en/cultur e/themes/illicit-trafficking-ofcultural-property/unesco-database-ofnational-cultural-heritagelaws/frequently-askedquestions/definition-of-the-culturalheritage/

Intangible
http://www.unesco.org/culture/ich/en/
Cultural

Heritage." . (2017) "Tangible Cultural http://www.unesco.org/new/en/cairo/c ulture/tangible-cultural-heritage/ 